\title{
Resolution of bleomycin-induced murine pulmonary fibrosis via a splenic lymphocyte subpopulation
}

Koichiro Kamio*, Arata Azuma, Kuniko Matsuda, Jiro Usuki, Minoru Inomata, Akemi Morinaga, Takeru Kashiwada, Nobuhiko Nishijima, Shioto Itakura, Nariaki Kokuho, Kenichiro Atsumi, Hiroki Hayashi, Tomoyoshi Yamaguchi, Kazue Fujita, Yoshinobu Saito, Shinji Abe, Kaoru Kubota and Akihiko Gemma

\begin{abstract}
Background: Idiopathic pulmonary fibrosis (IPF) is a progressive disease with high mortality, and the pathogenesis of the disease is still incompletely understood. Although lymphocytes, especially $\mathrm{CD}^{+} \mathrm{CD}^{2} 5^{+} \mathrm{FoxP} 3^{+}$regulatory $\mathrm{T}$ cells (Tregs), have been implicated in the development of IPF, contradictory results have been reported regarding the contribution of Tregs to fibrosis both in animals and humans. The aim of this study was to investigate whether a specific T cell subset has therapeutic potential in inhibiting bleomycin (BLM)-induced murine pulmonary fibrosis.

Methods: C57BL/6 mice received BLM (100 mg/kg body weight) with osmotic pumps (day 0), and pulmonary fibrosis was induced. Then, splenocytes or Tregs were adoptively transferred via the tail vein. The lungs were removed and subjected to histological and biochemical examinations to study the effects of these cells on pulmonary fibrosis, and blood samples were collected by cardiac punctures to measure relevant cytokines by enzyme-linked immunosorbent assay. Tregs isolated from an interleukin (IL)-10 knock-out mice were used to assess the effect of this mediator. To determine the roles of the spleen in this model, spleen vessels were carefully cauterized and the spleen was removed either on day 0 or 14 after BLM challenge.
\end{abstract}

Results: Splenocytes significantly ameliorated BLM-induced pulmonary fibrosis when they were administered on day 14. This effect was abrogated by depleting Tregs with an anti-CD25 monoclonal antibody. Adoptive transfer of Tregs on day 14 after a BLM challenge significantly attenuated pulmonary fibrosis, and this was accompanied by decreased production of fibroblast growth factor (FGF) 9-positive cells bearing the morphology of alveolar epithelial cells. In addition, BLMinduced plasma IL-10 expression reverted to basal levels after adoptive transfer of Tregs. Moreover, BLMinduced fibrocyte chemoattractant chemokine (CC motif) ligand-2 production was significantly ameliorated by Treg adoptive transfer in lung homogenates, accompanied by reduced accumulation of bone-marrow derived fibrocytes. Genetic ablation of IL-10 abrogated the ameliorating effect of Tregs on pulmonary fibrosis. Finally, splenectomy on day 0 after a BLM challenge significantly ameliorated lung fibrosis, whereas splenectomy on day 14 had no effect.

Conclusions: These findings warrant further investigations to develop a cell-based therapy using Tregs for treating IPF.

Keywords: Regulatory T cells, Idiopathic pulmonary fibrosis, Fibroblast growth factor 9, Interleukin-10, Chemokine (CC motif) ligand-2, Splenectomy

\footnotetext{
* Correspondence: bcway@nms.ac.jp

Department of Pulmonary Medicine and Oncology, Graduate School of

Medicine, Nippon Medical School, 1-1-5 Sendagi, Bunkyo-ku, Tokyo 113-8603,

Japan
}

(c) The Author(s). 2018 Open Access This article is distributed under the terms of the Creative Commons Attribution 4.0 International License (http://creativecommons.org/licenses/by/4.0/), which permits unrestricted use, distribution, and reproduction in any medium, provided you give appropriate credit to the original author(s) and the source, provide a link to the Creative Commons license, and indicate if changes were made. The Creative Commons Public Domain Dedication waiver (http://creativecommons.org/publicdomain/zero/1.0/) applies to the data made available in this article, unless otherwise stated. 


\section{Background}

Idiopathic pulmonary fibrosis (IPF) is a chronic lung condition that is characterized by progressive scarring of the lung parenchyma [1]. The course of the disease is difficult to predict; however, it generally involves progressive and relentless lung deterioration, curative therapy to quell ongoing fibrosis is not currently available, and the median survival time after diagnosis is 2.5 to 3.5 years [2]. Although the pathological processes underlying disease progression are not fully understood, current paradigms suggest a degenerative process involving alveolar epithelial cell injury and dysregulated repair, leading to aberrant accumulation and proliferation of myofibroblasts, which secrete excessive extracellular matrix (ECM) proteins and ultimately cause fibrotic lung scarring [3, 4]. Although the immunologic factors promoting these events remain unclear, these are important, ongoing areas of research $[5,6]$.

The significance of lymphocytes in IPF pathogenesis is undetermined. However, lymphocyte infiltration in areas of active fibroblastic proliferation in lungs with IPF have been identified and shown to exhibit an elevated $\mathrm{CD} 4 / \mathrm{CD} 8 \mathrm{~T}$ cell ratio that correlates positively with patient survival $[3,7,8]$. Among $\mathrm{T}$ lymphocytes, $\mathrm{CD}^{+}{ }^{+} \mathrm{CD} 25^{+} \mathrm{FoxP}^{+}$regulatory $\mathrm{T}$ cells (Tregs) play pivotal roles in maintaining immune system homeostasis, and significantly impaired Treg activity has been reported among IPF patients [9] although contradictory results have been reported regarding the role of Tregs in lung fibrosis [10, 11]. Supporting Kotsianidis et al. [9], the protective roles of Tregs using antibody-mediated Treg depletion in the fibrotic phase of bleomycin (BLM)-induced murine pulmonary fibrosis were reported [12]. However, whether Tregs ameliorate experimental pulmonary fibrosis in vivo is undetermined and a matter of debate, although BLMinduced murine pulmonary fibrosis cannot completely recapitulate human IPF.

Hence, to better understand the immunological nature of pulmonary fibrosis development, we utilized a wellestablished, BLM-induced murine pulmonary fibrosis model and investigated the effects of adoptive transfer of splenocytes on fibrosis. In addition, we examined the effect of anti-CD25 antibody-mediated neutralization of CD25 on splenocyte transfer. Moreover, to determine the effects of Tregs during a BLM challenge, we isolated Tregs from spleens and adoptively transferred them into mice with BLM-induced murine pulmonary fibrosis. The effect of the spleen was determined by performing splenectomies at different stages with the current fibrosis model. The current study is the first to describe the effects of adoptive Treg transfer into BLM-induced murine pulmonary fibrosis during the fibrotic phase. Our results will enhance the understanding of Treg-mediated resolution of fibrosis.

\section{Methods \\ Animals}

Nine-week-old male C57BL/6 mice were purchased from Charles River Laboratories Japan (Yokohama, Japan). We chose this strain because it is well characterized and is susceptible to BLM-induced pulmonary fibrosis. Interleukin (IL)-10 knock-out mice with C57BL genetic background (B6.129P2-Il10tm1Cgn/J) were purchased from The Jackson Laboratory (Bar Harbor, ME, USA). The experimental protocols in this study were approved by the animal care and use committee of Nippon Medical School (Tokyo, Japan, Approval Number; 27-098).

\section{BLM treatment and adoptive transfer of splenocytes} Osmotic pumps (ALZET model 2001; DURECT Corporation, Cupertino, CA, USA) containing $200 \mu \mathrm{L}$ saline, with or without BLM (100 mg/kg of mouse body weight; Nippon Kayaku Co., Tokyo, Japan), were implanted in recipient C57BL/6 mice on day 0 (Fig. 1a) [13]. Incision wounds were sealed using a surgical suture. BLM was continuously infused via the pumps over 7 days, according to the manufacturer's instructions.

Spleens were removed from donor C57BL/6 mice without BLM treatment and minced to obtain single-cell suspensions. Recipient C57BL/6 mice treated with BLM received $1 \times 10^{5}$ donor $\mathrm{C} 57 \mathrm{BL} / 6$ splenocytes on day 7 or 14 via caudal vein injection. On day 28 , mice were sacrificed and the lungs were removed for examination.

\section{Histological examination}

Lung samples were fixed in $10 \%$ formalin buffer (Wako Pure Chemical Industries, Ltd., Osaka, Japan) for histological examination. Paraffin sections (3.5 $\mu$ m-thick) were cut from fixed lungs, stained with hematoxylin and eosin (HE) to assess gross morphology and Masson's trichrome stain to visualize collagen deposition [14], and examined by microscopy. Lung fibrosis was measured using quantitative histology following Ashcroft's method [15].

\section{Antibody-mediated Treg depletion}

To deplete Tregs, we incubated single-cell suspensions of splenocytes $\left(1 \times 10^{5}\right)$ with $1 \mu \mathrm{L}$ of an anti-CD25 monoclonal antibody (mAb) (clone: PC61; BioLegend, San Diego, CA, USA) dissolved in sterile phosphatebuffered saline (PBS) for $20 \mathrm{~min}$ on ice. Then, these cells were adoptively transferred to BLM-treated mice on day 14 via the caudal vein. On day 28 , the mice were sacrificed, and the lungs were removed and subjected to $\mathrm{HE}$ and Masson's trichrome staining. The extent of lung fibrosis was measured by quantitative histology 
a $\downarrow \begin{aligned} & \text { Implantation of } \\ & \text { osmotic pump }\end{aligned}$ Day 0 $\downarrow$ Sacrifice<smiles>C=CC</smiles><smiles>[C]=C</smiles>

Bleomycin from day 0 to 6

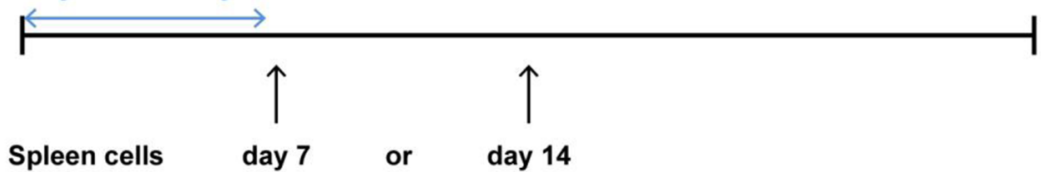

Study groups

Group 1: Saline

Group 2: Bleomycin

Group 3: Spleen cells on day 7

Group 4: Spleen cells on day 14

Group 5: Bleomycin + Spleen cells on day 7

Group 6: Bleomycin + Spleen cells on day 14

HE

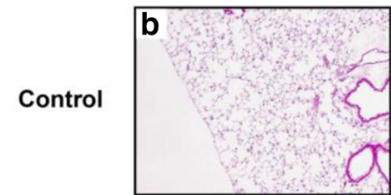

BLM
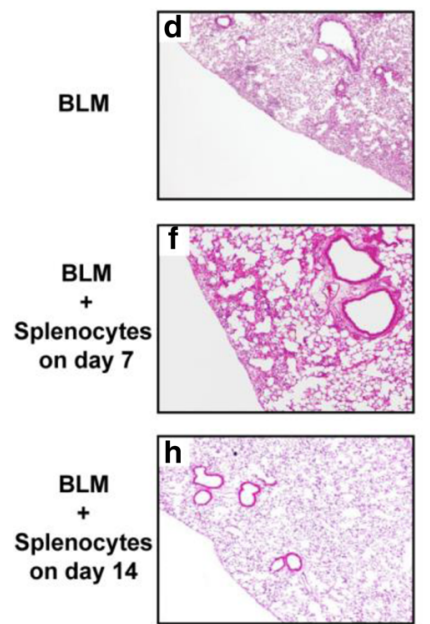

Masson's trichrome

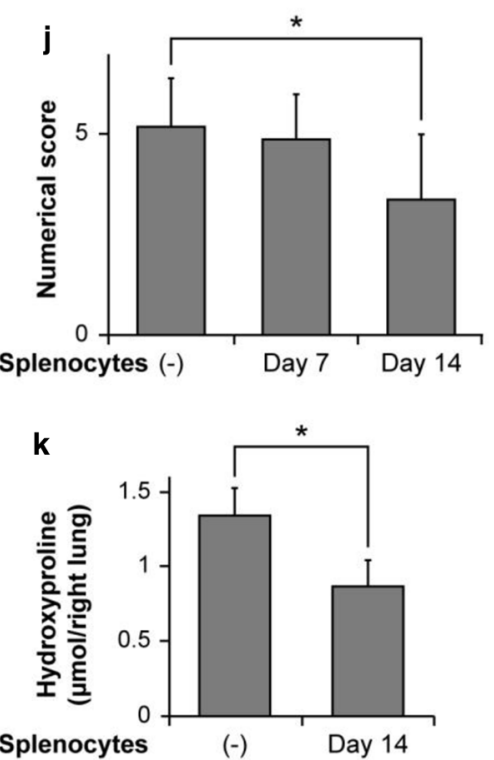

Fig. 1 Effect of adoptive transfer of splenocytes on bleomycin (BLM)-induced murine pulmonary fibrosis. a Outline of the experimental design used for the adoptive transfer of splenocytes. Osmotic pumps containing $200 \mu \mathrm{L}$ saline, with or without BLM (100 mg/kg mouse body weight), were implanted subcutaneously through a small incision in the back according to the manufacturer's instructions. BLM was infused continuously from day 0 to 6 . Splenocytes $\left(1 \times 10^{5} /\right.$ mouse) were injected via the tail vein either on day 7 or 14 after initiating BLM treatment. On day 28 post-BLM injection, the mice were sacrificed and their lungs were removed for analyses. Each group included at least 6 mice. $\mathbf{b}-\mathbf{i}$ Increased fibrosis and collagen deposition observed in the lungs of BLM-treated mice were attenuated by the infusion of splenocytes on day 14 post-BLM treatment. Typical photomicrographs of hematoxylin and eosin (HE) and Masson's trichrome staining of the left lungs from saline-treated and BLMtreated mice, with or without splenocyte infusion $\left(1 \times 10^{5}\right.$ cells/mouse). Magnification $\times 10$. $\mathbf{j}$ The extent of lung fibrosis was measured by quantitative histology according to Ashcroft's method on day 28 to determine the anti-fibrotic effects of splenocytes in the lungs of BLM-treated mice. Because BLM administration with osmotic pumps causes lung fibrosis predominantly in the subpleural regions, subpleural fibrosis between the groups was compared using a numerical scale. Adoptive transfer of splenocytes on day 14 significantly attenuated the numerical score, which was increased by BLM administration. ${ }^{*} P<0.05 . n=6-8$ mice/group. $\mathbf{k}$ The hydroxyproline content in the lungs was measured on day 28. Adoptive transfer of splenocytes on day 14 post-treatment significantly reduced the hydroxyproline content in the lungs when compared with the BLM treated group $\left({ }^{*} P<0.05\right) . n=3$ mice for the BLM group, $n=4$ mice for the BLM + splenocyte on day 14 group 
according to Ashcroft's method to determine the effect of CD25 neutralization with the anti-CD25 mAb.

\section{Fluorescence-activated cell sorting (FACS) analysis of splenocytes}

Splenocyte subpopulations were analyzed by evaluating the relative proportions of Tregs, macrophages, and B cells. Single-cell suspensions of splenocytes were stained with anti-mouse CD4 (BioLegend) and CD25 (eBioscience, Waltham, MA, USA) antibodies to analyze Tregs. To analyze macrophages and their polarization, splenocytes were stained with anti-mouse F4/80 (BioLegend), CD80 (eBioscience), and CD206 (BioLegend) antibodies. Splenocytes were stained with an antibody against CD45R (B220; BioLegend) for B cell detection. To eliminate nonspecific staining, isotype- control antibodies, matched to the surface marker antibody's host species and class, were used. FACS analysis was performed using a BD FACSCanto II and BD FACSVerse flow cytometers (BD Biosciences, San Diego, California, USA). Data collected were analyzed with FlowJo software (Tree Star, Inc., Ashland, Oregon, USA).

\section{Isolation of Tregs from the spleen and adoptive transfer to BLM-treated mice}

After single-cell suspensions were obtained from the spleens of C57BL/6 mice, Tregs were purified using a MiniMacs $\mathrm{CD} 4{ }^{+} \mathrm{CD} 25^{+}$Regulatory T-cell Isolation Kit (Miltenyi Biotec, Auburn, CA, USA) according to the manufacturer's instructions. To achieve the highest purity, we separated positive and negative cell fractions by passing the cells through a second column. BLM-treated recipient $\mathrm{C} 57 \mathrm{BL} / 6$ mice received an intravenous tail vein injection of $1 \times 10^{6}$ isolated donor cells on day 14 after initiating BLM treatment. The dose of Tregs was determined according to a study performed by D'Alessio FR and colleagues [16]. Mice were sacrificed on day 28, and the lungs were removed and subjected to histological and biochemical analyses. Blood collected by cardiac punctures and lung homogenates were subjected to cytokine or chemokine analyses.

\section{Hydroxyproline measurement}

The total collagen content of the right lung was determined by hydroxyproline assay [17]. After acid hydrolysis of the right lung with $12 \mathrm{~N} \mathrm{HCl}$ at $100{ }^{\circ} \mathrm{C}$ for $20 \mathrm{~h}$ in a sealed glass tube (Iwaki, Tokyo, Japan), the hydroxyproline content was determined by high-performance liquid chromatography.

\section{Immunohistochemistry for fibroblast growth factor (FGF)} 9

Sections of paraffin-embedded lung lobes were deparaffinized and rehydrated. Antigen retrieval was achieved by boiling at $105{ }^{\circ} \mathrm{C}$ for $7 \mathrm{~min}$ in $10 \mathrm{mM}$ citrate buffer ( $\mathrm{pH}$ 6.0), followed by gradual cooling to room temperature. Then, the sections were treated with $3 \%$ hydrogen peroxide in methanol for $20 \mathrm{~min}$ and blocked with 10\% normal goat serum (NICHIREI BIOSCIENCES, INC., Tokyo, Japan) at room temperature for 10 min. Sections were incubated with an anti-FGF9 polyclonal antibody (Abcam, Cambridge, MA, USA) for $30 \mathrm{~min}$ at room temperature. For FGF9 staining, tissue sections were incubated with a secondary anti-rabbit antibody (NICHIREI BIOSCIENCES, INC.) for $30 \mathrm{~min}$ at room temperature. FGF9 expression was visualized using Histofine Simple Stain Mouse MAX-PO (R) and Histofine Simple Stain AEC Solution (NICHIREI BIOSCIENCES, INC.).

Enzyme-linked immunosorbent assay (ELISA) experiments Mouse plasma FGF9 and IL-10 levels were measured using ELISA kits purchased from Cloud-Clone Corp. (Houston, TX, USA) and R\&D Systems Inc. (Minneapolis, MN, USA), respectively. Approximately 0.5-1. $0 \mathrm{~mL}$ of blood was collected from each mouse on day 28 by cardiac puncture, placed in a tube containing EDTA and aprotinin, incubated at $4-8{ }^{\circ} \mathrm{C}$ for $15 \mathrm{~min}$, and then centrifuged at $5000 \mathrm{rpm}$ for $2 \mathrm{~min}$ at $4{ }^{\circ} \mathrm{C}$ to separate the plasma. Plasma samples were stored at $-20{ }^{\circ} \mathrm{C}$ until analysis. For chemoattractant chemokine (CC motif) ligand 2 (CCL2) measurement in the lungs, the right lung of each mouse was added to 1 .

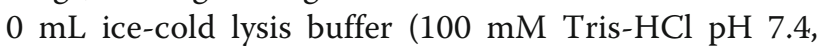
$150 \mathrm{mM} \mathrm{NaCl}, 1 \mathrm{mM}$ EDTA, and protease inhibitor cocktail [Complete mini; Roche Diagnostics, Basel, Switzerland]), and then homogenates were prepared with a 2-mL tissue grinder (Wheaton Industries, Millville, New Jersey, USA). After centrifuging the homogenate at $10,000 \times \mathrm{g}$ for $5 \mathrm{~min}$ at $4{ }^{\circ} \mathrm{C}$, supernatants were prepared from the lung homogenates, and CCL2 concentration was measured using ELISA kits from Cloud-Clone Corp.

ELISA was performed to determine the concentrations of FGF9, IL-10, and CCL2 following the manufacturer's protocols. Briefly, supernatants of each sample were diluted in PBS, and $100 \mu \mathrm{L}$ of the diluted samples was assayed with the kits. The optical density was measured at a wavelength of $450 \mathrm{~nm}$ using a microtiter plate reader. All samples were measured in duplicate.

\section{Immunohistochemistry for col-I and CD45}

Sections of paraffin-embedded lung lobes were deparaffinized and rehydrated. Antigen retrieval was achieved by boiling at $105{ }^{\circ} \mathrm{C}$ for $7 \mathrm{~min}$ in $10 \mathrm{mM}$ citrate buffer ( $\mathrm{pH}$ 6.0) (LSI Medience Corporation, Tokyo, Japan), followed by gradual cooling to room temperature. Then, 
the sections were blocked with $1 \%$ bovine serum albumin (BSA) (Sigma-Aldrich Corporation, St. Louis, MO, USA) for $20 \mathrm{~min}$ at room temperature. Tissue sections were incubated with anti-CD45 and anti-Col-I antibodies (Abcam) overnight at $4{ }^{\circ} \mathrm{C}$ followed by Alexa Fluor 488-conjugated and Alexa Fluor 568-conjugated antibodies (Abcam) for $1 \mathrm{~h}$ at room temperature. VECTASHIELD mounting medium dispersed over the entire section to counterstain the nuclei with 4',6-diamidino-2phenylindole (DAPI) (Vector Laboratories, Inc. Burlingame, CA, USA).

\section{Immunohistochemistry for FGF9 and E-cadherin}

Sections of paraffin-embedded lung lobes were deparaffinized and rehydrated. Antigen retrieval was achieved by boiling at $105{ }^{\circ} \mathrm{C}$ for $7 \mathrm{~min}$ in $10 \mathrm{mM}$ citrate buffer ( $\mathrm{pH}$ 6.0), followed by gradual cooling to room temperature. Then, the sections were blocked with $1 \% \mathrm{BSA}$ for $20 \mathrm{~min}$ at room temperature. For FGF9 staining, tissue sections were incubated with an anti-FGF9 antibody (Abcam) for $1 \mathrm{~h}$ at room temperature followed by an Alexa Fluor 568conjugated antibody (Abcam) for $30 \mathrm{~min}$ at room temperature. Subsequently, they were blocked with $1 \%$ BSA for $20 \mathrm{~min}$ at room temperature and incubated with an anti-E-cadherin antibody (Merck KGaA, Darmstadt, Germany) at $4{ }^{\circ} \mathrm{C}$ overnight followed by an Alexa Fluor 488 antibody for $30 \mathrm{~min}$ at room temperature. VECTASHIELD mounting medium dispersed over the entire section to counterstain the nuclei with DAPI.

\section{Splenectomy}

Either on day 0 or 14 after BLM challenge, the abdominal cavity of mice was opened above the left kidney during isoflurane anesthesia. Then, the spleen vessels were carefully cauterized and the spleen was removed. On day 28 , mice were sacrificed and lungs were subjected to HE and Masson's trichrome staining to quantify the fibrotic score using Ashcroft method.

\section{Statistical analysis}

Animal experiments involved at least 6 mice in each treatment group, unless otherwise stated. Comparisons among multiple groups were analyzed by 1 -way analysis of variance with the Tukey-Kramer post-hoc correction to adjust for multiple comparisons. An unpaired 2-tailed Student's $t$ test was used for single comparisons. Data were analyzed using JMP 9 software, version 9.0.3 (SAS Institute Inc., Cary, NC, USA). Differences were considered statistically significant when $P$ values were less than 0.05 . Data are expressed as the mean \pm standard deviation.

\section{Results}

Resolution of BLM-induced murine pulmonary fibrosis by the adoptive transfer of splenocytes

Because whole splenocytes can ameliorate LPS-induced lung injury in mice [16], as an initial assessment, we examined the potency of the adoptive transfer of splenocytes in ameliorating BLM-induced murine pulmonary fibrosis. BLM (100 mg/kg body weight) was administered to C57BL/6 mice using osmotic pumps (day 0, Fig. 1a). Splenocytes were prepared from the spleens of C57BL/6 mice without BLM treatment and injected $\left(1 \times 10^{5}\right.$ cells/ mouse) via the caudal vein on either day 7 or 14 postBLM challenge. Mice were sacrificed on day 28 , and the lungs were removed and subjected to histological examination. Lung histological data obtained on day 28 postBLM administration showed focal fibroplasias with destruction of the alveolar wall in the group receiving BLM (Fig. 1d and e) but not in the saline group (Fig. 1b and c). Injection of splenocytes on day 14 ameliorated the lesions (Fig. 1h and i); however, no obvious effect of splenocyte injection was observed on day 7 (Fig. If and g). To quantify the anti-fibrotic effects of splenocytes in the lungs of BLM-treated mice, we determined the extent of lung fibrosis by quantitative histology according to Ashcroft's method on day 28 post-treatment. Because BLM administration with osmotic pumps causes lung fibrosis predominantly in the subpleural regions $[18,19]$, subpleural fibrosis between the groups was compared using a numerical scale. Two blinded observers [KKa and MI] quantified fibrosis in each section. Splenocytes significantly attenuated the fibrosis score when administered to BLM-treated mice on day 14 (Fig. 1 j, " $P<0.05$ ); however, administration of splenocytes on day 7 had no effect on pulmonary fibrosis. To characterize the anti-fibrotic effects of splenocytes, we assayed the hydroxyproline content in the lungs on day 28. As shown in Fig. 1k, the adoptive transfer of splenocytes on day 14 post-BLM challenge significantly reduced the hydroxyproline content in the lungs when compared with the BLM treated group $\left({ }^{*} P<0.05\right)$.

\section{Effect of splenocytes depleted of Tregs on BLM-induced murine pulmonary fibrosis}

Splenocytes have been reported to be rich in Tregs, and D'Alessio et al. reported that Tregs contributed to the resolution of LPS-induced lung injury in mice [16]. Given that the resolution of BLM-induced murine pulmonary fibrosis was dependent on spleen cells due to their suppressive properties, we hypothesized that specific lymphocyte subsets among splenocytes may be critical in this process. To begin understanding the potential contribution of those cells to BLM responses, we depleted Tregs using an anti-CD25 mAb. Splenocytes were incubated with the anti-CD25 mAb, after which they were injected via the caudal vein on day 14 post- 
BLM treatment. On day 28, the mice were sacrificed, and their lungs were removed and subjected to histological examination and biochemical analyses (Fig. 2). As shown in Fig. 2e and f, splenocytes depleted of Tregs using an anti-CD25 mAb lost the potential to ameliorate BLM-induced murine pulmonary fibrosis. To quantify this effect, we determined the extent of lung fibrosis by quantitative histology on day 28, according to Ashcroft's method. Two blinded observers [KKa and MI] quantified the degree of fibrosis in each section. Amelioration of BLM-induced murine pulmonary fibrosis by splenocytes was significantly abrogated by Treg depletion with the anti-CD25 mAb (Fig. 2g, * $P<0.01$ ). These data indicated that CD25-mediated Treg depletion promotes increased lung fibrosis, thereby suggesting that immunomodulatory cells (including Tregs) might mediate the effects of splenocytes on pulmonary fibrosis resolution. A similar trend in the numerical score was observed on the lung hydroxyproline content, although statistical significance was not achieved (Fig. 2h, $P=0$. 16).

To characterize splenocytes, we examined the number of CD4 and CD25 double-positive cells by immunostaining and FACS analysis of spleen digests from BLMuntreated C57BL/6 mice. As shown in Fig. 2i, Tregs accounted for approximately $11 \%$ of the splenocytes. Furthermore, we assayed macrophage subpopulations because diverse activation states of macrophages can result in phenotypic polarization and the formation of pro-inflammatory M1 and pro-healing M2 type macrophages [20]. As shown in Fig. 2j, approximately $10 \%$ of splenocytes were macrophages (F4/80), most of which

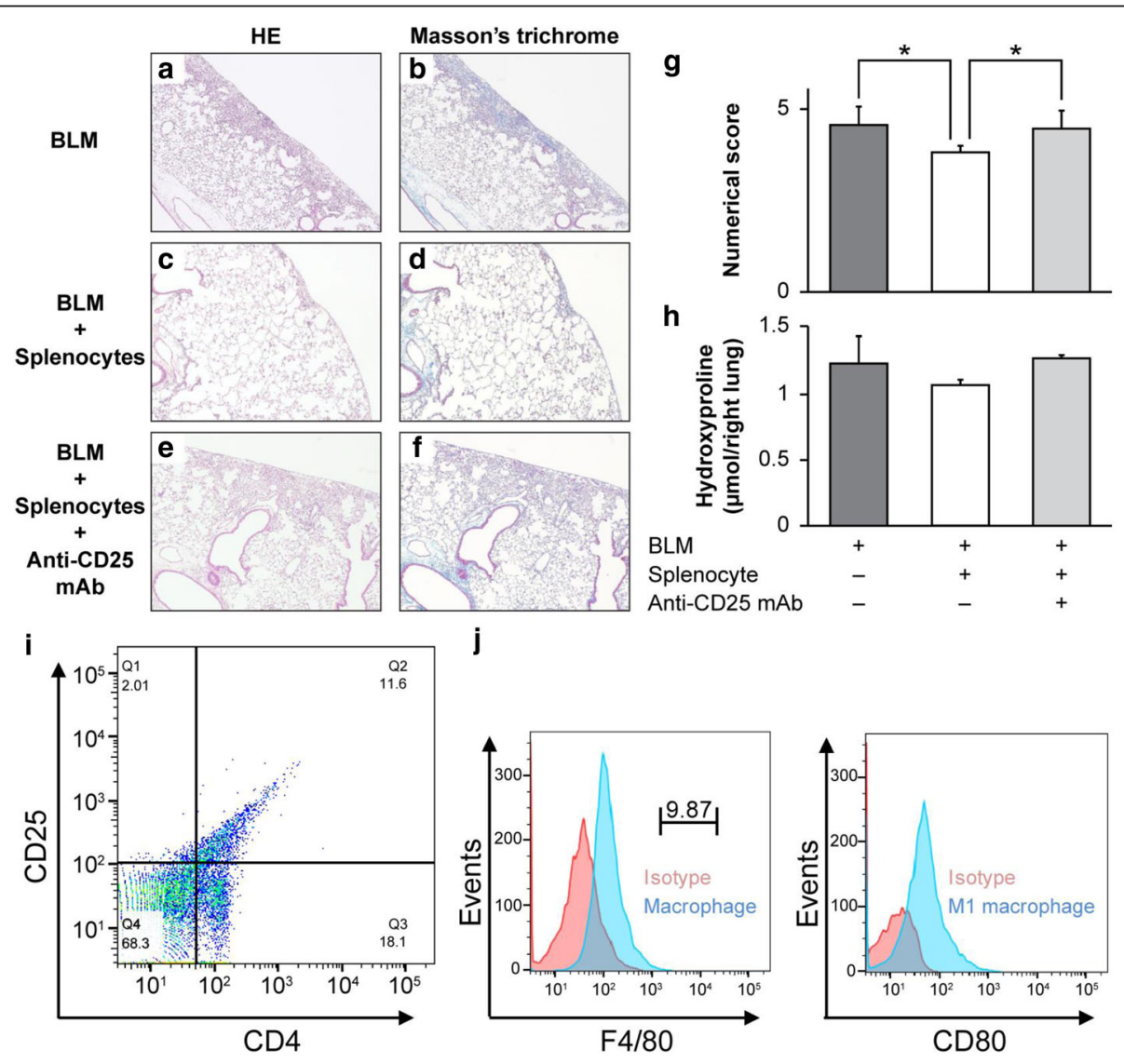

Fig. 2 Effect of splenocytes depleted of Tregs on bleomycin (BLM)-induced murine pulmonary fibrosis. a-f Splenocyte suspensions $\left(1 \times 10^{5}\right.$ cells) obtained from C57BL/6 mice were incubated with $1 \mu \mathrm{L}$ of an anti-CD25 monoclonal antibody (mAb) for 20 min on ice, after which they were injected via the caudal vein on day 14 post-BLM treatment. On day 28, the mice were sacrificed and the lungs were removed and subjected to hematoxylin and eosin (HE) and Masson's trichrome staining. $\mathbf{g}$ The extent of lung fibrosis was measured by quantitative histology according to Ashcroft's method to determine the effect of CD25 neutralization with the anti-CD25 mAb. Treatment of splenocytes with the anti-CD25 $\mathrm{mAb}$ abrogated the anti-fibrotic effect of splenocytes in BLM-induced pulmonary fibrosis. ${ }^{*} P<0.01 . n=7$ mice/group. $\mathbf{h}$ The hydroxyproline content in the lungs was measured on day 28. A similar trend in the numerical score was observed in the lung hydroxyproline content, although statistical significance was not achieved. $n=4$ mice for each group. Splenocytes were subjected to FACS analysis to identify Tregs (i) and macrophages (j). Tregs accounted for approximately $11 \%$ of the splenocytes. Macrophages consisted of approximately $10 \%$ splenocytes, most of which had the M1 phenotype 
were of the M1 phenotype, in agreement with previous data published elsewhere [21]. B cells constituted approximately $30 \%$ of the splenocytes (data not shown).

\section{Adoptive transfer of isolated Tregs to BLM-treated mice with pulmonary fibrosis}

The data obtained using the anti-CD25 mAb prompted us to examine whether Tregs potently resolve BLMinduced pulmonary fibrosis in mice. To that end, Tregs isolated from spleens of donor C57BL/6 mice were adoptively transferred to recipient mice $\left(1 \times 10^{6}\right.$ cells/ mouse) via the caudal vein on day 14 post-BLM challenge (Fig. 3a). Because adoptive transfer of splenocytes on day 14 ameliorated fibrosis, which was abrogated by an anti-CD25 antibody, this time point was selected for the Treg transfers. Thereafter, on day 28 , mice were sacrificed, and the lungs were removed and subjected to immunohistochemical and biochemical analyses (Fig. 3). In addition, blood was collected by cardiac punctures to analyze the FGF9 and IL-10 levels, and lung homogenates were prepared to measure CCL2 levels. As shown in Fig. $3 \mathrm{~h}$ and i, adoptively transferring Tregs on day 14 ameliorated the lesions. To quantify the anti-fibrotic effects of Tregs in the lungs of BLM-treated mice, we determined the extent of lung fibrosis using a quantitative histology according to Ashcroft's method on day 28. Two blinded observers [KKa and AM] quantified fibrosis in each section. Tregs significantly attenuated the fibrosis score when adoptively transferred to BLM-treated mice on day 14 (Fig. 3j, "P<0.01). To further characterize the anti-fibrotic effects of Tregs, we quantified the hydroxyproline content in the lungs on day 28. As shown in Fig. 3k, adoptive transfer of Tregs significantly reduced the hydroxyproline content in the lungs when compared with the BLM treated group $(" P<0.05)$.

\section{Effect of adoptively transferred Tregs on FGF9 expression in BLM-induced murine pulmonary fibrosis}

FGF9 is a neuroimmune system molecule with manifold effects on embryonic development and mesenchymal proliferation that may be involved in human lung fibrosis [22]. While in vivo data demonstrated that antibodymediated Treg depletion augmented FGF9 expression in mice overexpressing TGF- $\beta 1$ [23], the effect of adoptively transferred Tregs on FGF9 expression in BLMinduced lung fibrosis is not yet described. To determine whether Tregs affect FGF9 expression, we performed immunohistochemistry against FGF9. The control and Treg transferred groups had undetectable FGF9 expression (data not shown), which was consistent with a prior report [23]. In contrast, FGF9-positive cells bearing the morphology of alveolar epithelial cells markedly increased in the setting of BLM-induced pulmonary fibrosis (Fig. 4a), whereas FGF9-positive cells decreased following the adoptive transfer of Tregs (Fig. 4b). Composite data represented as the number of FGF9-positive cells revealed that the adoptive transfer of Tregs reduced FGF9positive cells by $54.2 \%$, as compared to BLM-treated mice without adoptively transferred Tregs (Fig. 4c). To confirm that FGF9-positive cells are epithelial cells, we performed dual staining of these cells using anti-FGF9 and anti-Ecadherin antibodies. As shown in Fig. $4 \mathrm{~d}-\mathrm{f}$, most of the FGF9-positive cells (red) expressed E-cadherin (green). In addition, we determined the plasma FGF9 levels by ELISA. As shown in Fig. 4g, the plasma FGF9 concentration appeared to increase with BLM treatment, as compared to saline-treated control mice. The increase showed a trend to be reduced to control levels by the adoptive transfer of Tregs, although statistical significance was not achieved.

\section{Effect of Tregs on a soluble mediator of inflammation}

Tregs are conventionally associated with the production of classic anti-inflammatory cytokines including IL-10, TGF- $\beta$, and IL-35, consistent with their anti-inflammatory functions [24]. Among these cytokines, IL-10 has been reported to inhibit BLM-induced lung injury in mice $[25,26]$. Therefore, we hypothesized that the Treg-mediated anti-fibrotic effect was due in part to IL-10 production from adoptively transferred Tregs. To test this hypothesis, we collected plasma samples from BLM-treated and Treg-transferred mice, and then assessed IL-10 levels in ELISAs. The data indicated that the plasma IL-10 concentration increased by up to 3.0fold after BLM treatment (Fig. 5). Unexpectedly, the adoptive transfer of Tregs significantly inhibited IL-10 production in mouse plasma induced by BLM administration.

\section{Effect of Tregs from IL-10 knock-out mice on BLM- induced murine pulmonary fibrosis}

The above data prompted us to examine the effect of Tregs isolated from IL-10 knock-out mice on pulmonary fibrosis. Tregs isolated from IL-10 knock-out mice spleens were adoptively transferred via the tail vein on day 14 after a BLM-challenge according to the protocol described in Fig. 3a. On day 28, the mice were sacrificed, and the lungs were removed and subjected to immunohistochemical and biochemical analyses (Fig. 6). As shown in Fig. 6e and f, adoptive transfer of Tregs isolated from IL-10 knock-out mice did not ameliorate the fibrosis. We quantified these results using quantitative histology according to Ashcroft's method on day 28. Two blinded observers [KKa and AM] quantified fibrosis in each section. Although statistical significance was not achieved, a trend was observed indicating that the transfer of Tregs isolated from IL-10 knock-out mice did not attenuate the fibrosis score when compared with transferring Tregs obtained from wild-type C57BL/6 mice (Fig. 6g). We also quantified the hydroxyproline content in the lungs on day 28. As shown in Fig. $6 \mathrm{~h}$, a similar trend for the numerical score was observed. 
a Implantation of

Day 0

Day 28

$\downarrow$

$\downarrow$

Bleomycin from day 0 to 6

$\longleftrightarrow$

Study groups

Group 1: Saline

Group 2: Bleomycin

Group 3: Tregs on day 14

Group 4: Bleomycin + Tregs on day 14

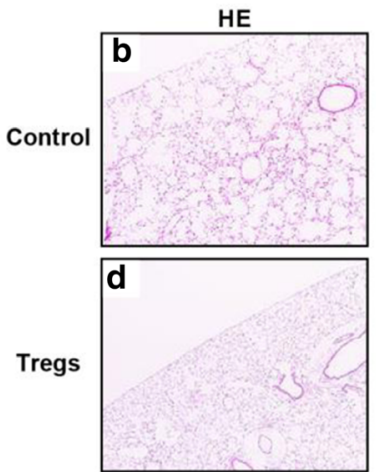

Masson's trichrome
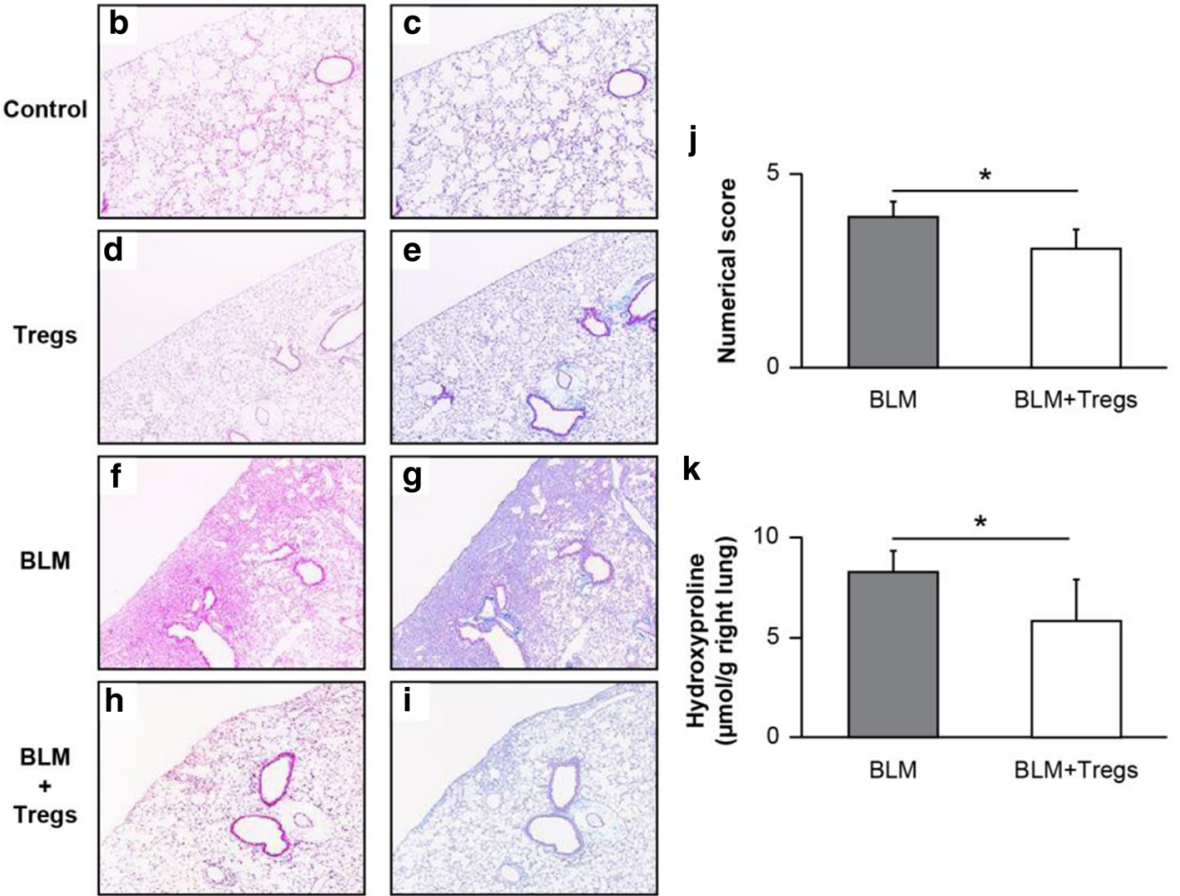

$\mathbf{k}$
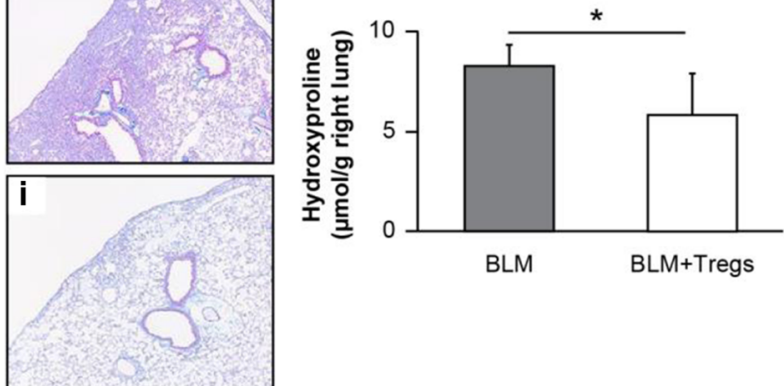

Fig. 3 Effect of adoptively transferring Tregs on bleomycin (BLM)-induced murine pulmonary fibrosis. a Outline of the experimental design used for the adoptive transfer of Tregs. Osmotic pumps containing $200 \mu \mathrm{L}$ saline, with or without bleomycin (BLM; $100 \mathrm{mg} / \mathrm{kg}$ mouse body weight), were implanted subcutaneously through a small incision in the back according to the manufacturer's instructions. BLM was infused continuously from day 0 to 6 . Tregs $\left(1 \times 10^{6}\right.$ /mouse) were injected via the tail vein on day 14 after initiating BLM treatment. On day 28 post-BLM challenge, the mice were sacrificed and their lungs were removed and blood was collected for analyses. Each group included at least 6 mice unless otherwise stated. $\mathbf{b}$-i Increased fibrosis and collagen deposition observed in the lungs of BLM-treated mice were attenuated by the adoptive transfer of Tregs $\left(1 \times 10^{6}\right.$ /mouse) on day 14 post-BLM challenge. Representative photomicrographs following hematoxylin and eosin (HE) and Masson's trichrome staining of the right lungs from saline-treated and BLM-treated mice, with or without adoptively transferred Tregs. Magnification $\times 40$. $\mathbf{j}$ The extent of lung fibrosis was measured by quantitative histology according to Ashcroft's method on day 28 to determine the anti-fibrotic effects of Tregs in the lungs of BLM-treated mice. The adoptive transfer of Tregs on day 14 post-treatment significantly attenuated the numerical score, which was increased by BLM treatment. ${ }^{*} P<0.01 . n=7$ mice/group. $\mathbf{k}$ The hydroxyproline content in the lungs was measured on day 28. The adoptive transfer of Tregs on day 14 post-treatment significantly reduced the hydroxyproline content when compared with the BLM treated group. ${ }^{*} P<0.05 . n=4$ mice for the BLM group, $n=3$ mice for the BLM + Tregs group 

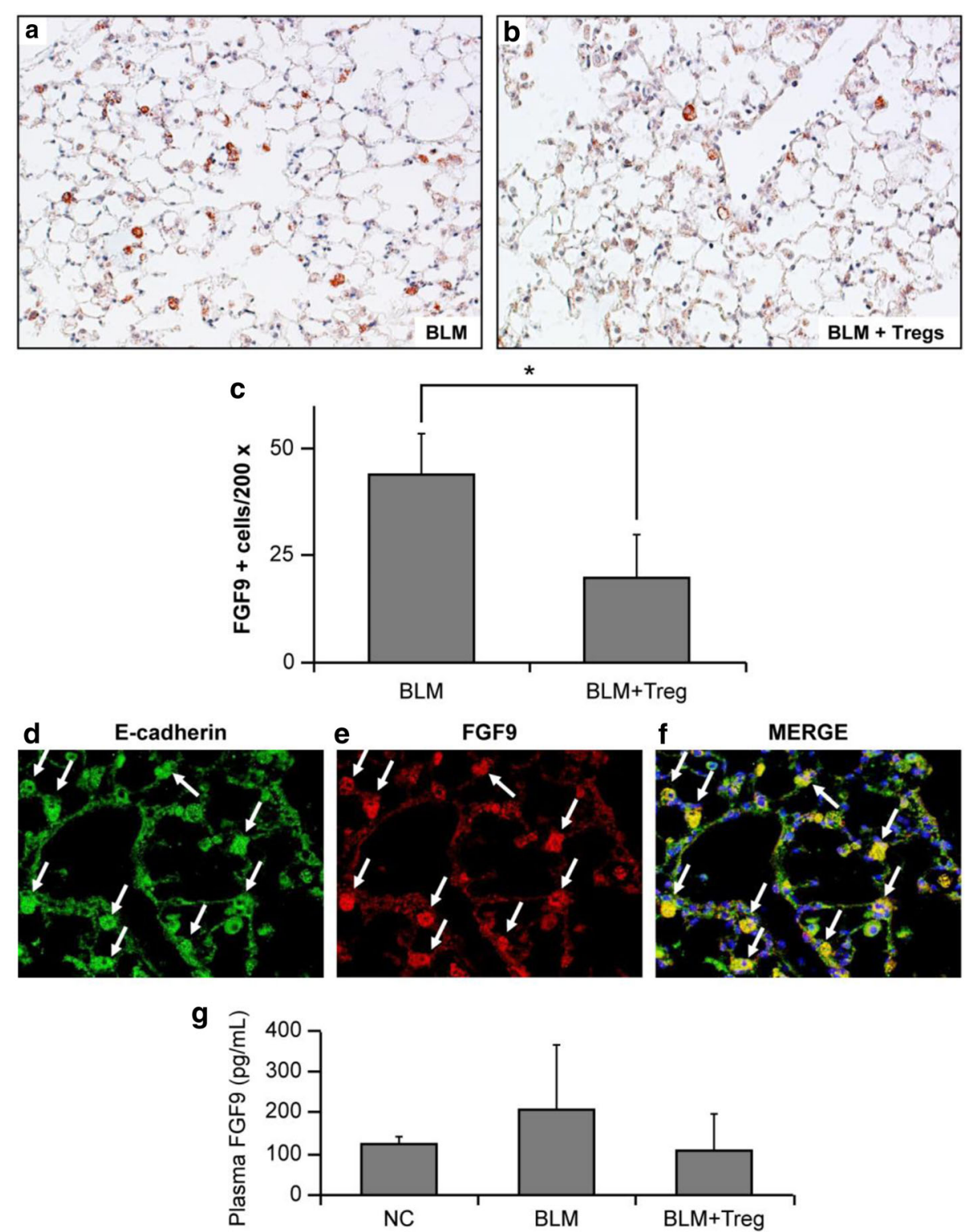

Fig. 4 Adoptively transferred Tregs ameliorated the accumulation of fibroblast growth factor (FGF) 9-expressing cells. Immunohistochemical staining for FGF9 (red) in mouse lungs with BLM-induced pulmonary fibrosis, without or with adoptively transferred Tregs (a and $\mathbf{b}$, respectively). FGF9-positive cells bearing the morphology of alveolar epithelial cells markedly increased by BLM treatment (a), and this increase was attenuated by the adoptive transfer of Tregs (b). Tissue sections were counterstained with hematoxylin. Representative data from each group are presented. c Composite data represented as the number of FGF9-positive cells per $200 \times$ field. $n=3$ for BLM, $n=4$ for BLM + Tregs. ${ }^{*} P<0.05$. $\mathbf{d}-\mathbf{f}$ Dual staining for E-cadherin (green; d) and FGF9 (red; e) was performed with lung sections on day 28 after BLM treatment. The merged images (yellow; f) represent co-staining for E-cadherin and FGF9, indicating that both, FGF9 and E-cadherin, are expressed by alveolar epithelial cells. g Plasma samples from BLM-treated and Treg-transferred mice were collected by cardiac punctures on day 28 post-BLM challenge, and FGF9 levels were measured by ELISA. The plasma FGF9 concentration appeared to increase following BLM treatment. A trend was observed that the increase tended to be reduced to basal levels by the adoptive transfer of Tregs. $n=3-4$ mice/group. NC; normal control

\section{Effect of Tregs on fibrocyte chemoattractant CCL2} production and fibrocyte accumulation in the lungs Bone marrow-derived circulating fibrocytes are mesenchymal progenitor cells that express markers compatible with leukocytes, hematopoietic progenitor cells, and fibroblasts [27]. They are chemotactically recruited to sites of tissue injury by chemokines, including CCL2 [28], and promote fibrotic responses [29]. Because Tregs have been found to inhibit fibrocyte recruitment [23], we hypothesized that Treg adoptive transfer affects chemokine production in the lungs. To determine this, we measured CCL2 production by 


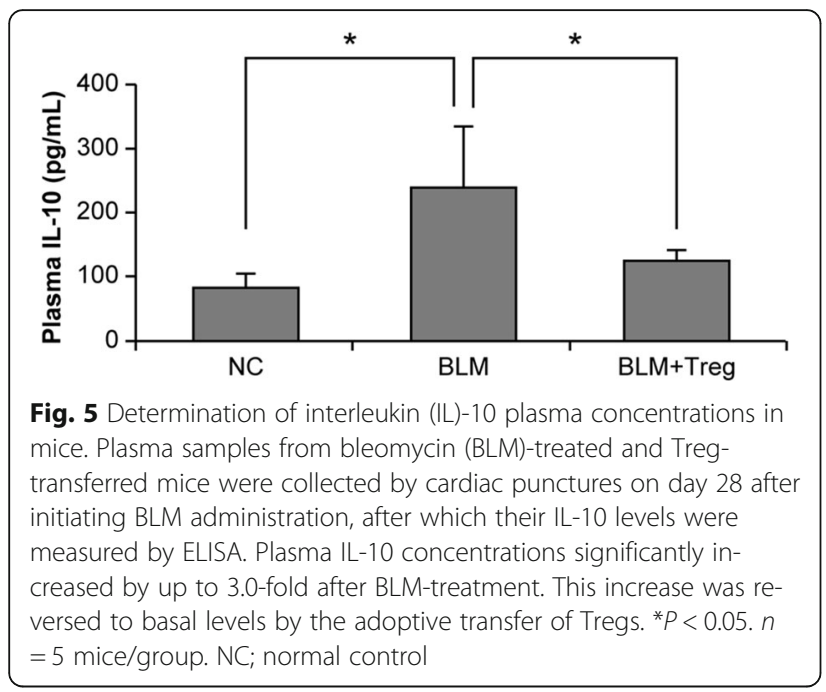

ELISA in BLM-induced murine pulmonary fibrosis lungs that had received Treg adoptive transfer. As shown in Fig. 7a, BLM treatment increased CCL2 production by up to 2.0 -fold in the lungs. Adoptive transfer of Tregs significantly reversed this increase to the basal levels, which was accompanied by reduced accumulation of fibrocytes in the lungs (Fig. $7 \mathrm{~b}-\mathrm{g}$ ).
Effect of splenectomy on BLM-induced murine pulmonary fibrosis

Mouse splenocytes can be reduced in number by BLM administration [30], causing us to speculate that spleen is a reservoir of Tregs. Because our observation suggested the participation of spleen cells in the amelioration of pulmonary fibrosis, we were prompted to examine the effect of splenectomy. BLM was administered to $\mathrm{C} 57 \mathrm{BL} / 6$ mice using osmotic pumps (day 0 , Fig. 8a), after which the spleen vessels were carefully cauterized and spleen was removed either on day 0 or 14 . On day 28 , the mice were sacrificed and the lungs were subjected to HE and Masson's trichrome staining to quantify the fibrotic score, using Ashcroft's method. Two blinded observers [KKa and AM] quantified the degree of fibrosis in each section. As shown in Fig. $8 \mathrm{~b}-\mathrm{f}$, splenectomy on day 0 significantly ameliorated pulmonary fibrosis, whereas that on day 14 had no effect on fibrosis (data not shown).

\section{Discussion}

Here, we demonstrated for the first time (to our knowledge) that splenocytes can potently ameliorate pulmonary fibrosis in vivo, using a well-characterized, BLMinduced murine pulmonary fibrosis model. This effect

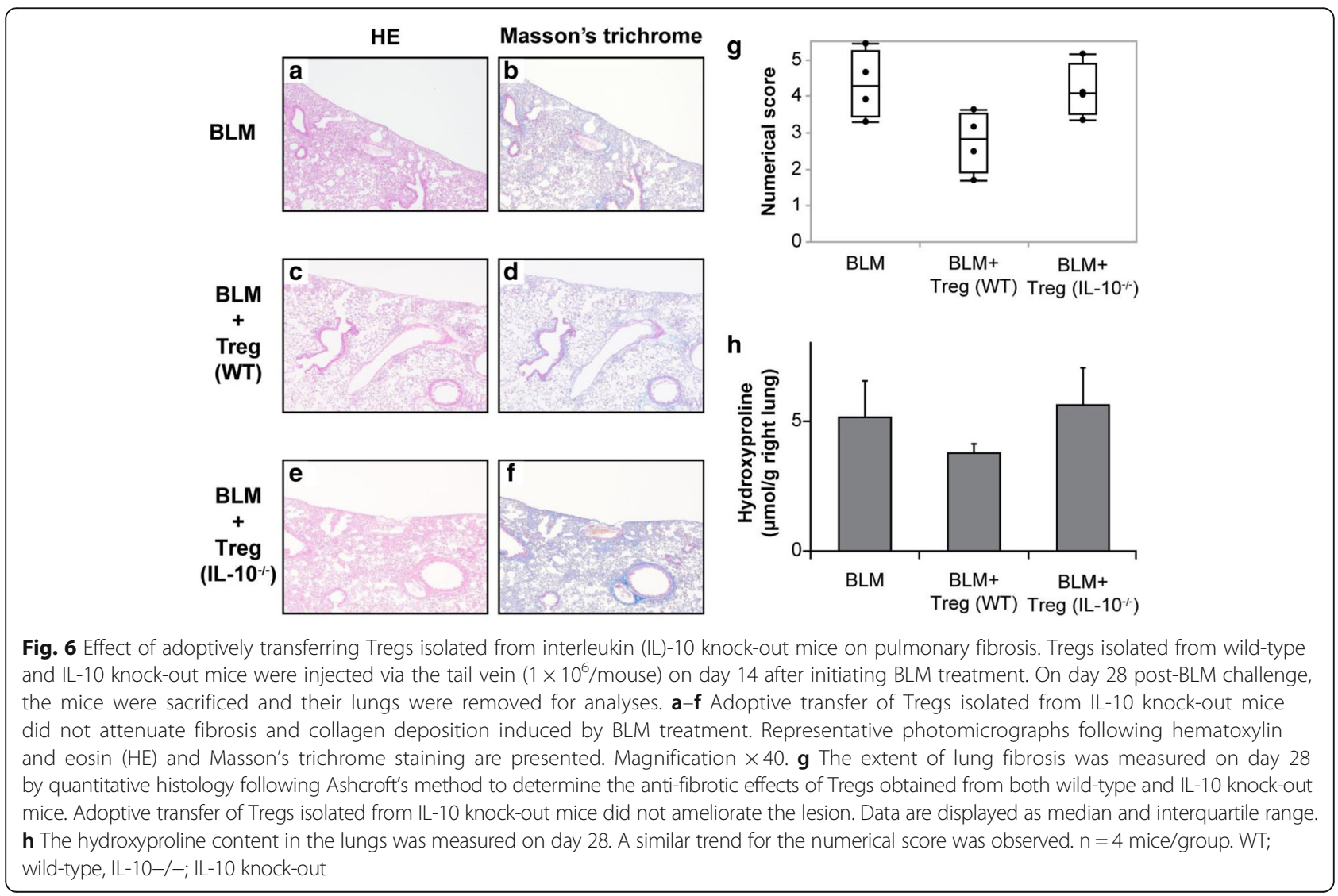




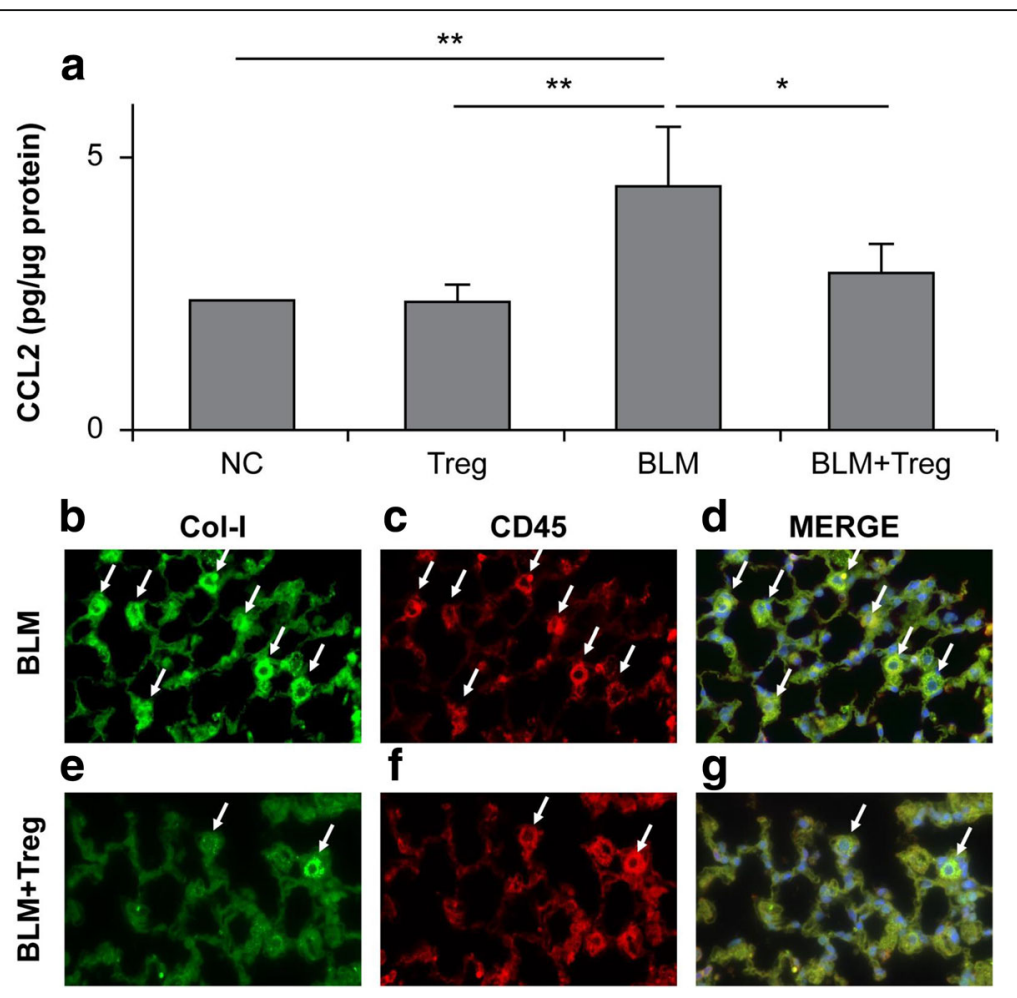

Fig. 7 Adoptively transferred Tregs reduced chemokine (CC motif) ligand-2 (CCL2) production and fibrocyte accumulation. a CCL2 levels in lung digests were measured by performing ELISA on day 28 post-BLM challenge. CCL2 production was significantly increased in BLM-treated mouse lungs compared with that in lungs from saline-treated and Treg-transferred mice. Adoptive transfer of Tregs significantly attenuated CCL2 production in BLM-treated mice. ${ }^{*} P<0.05$, ${ }^{* *} P<0.01 . \mathrm{n}=3$ mice/group. NC; normal control. $\mathbf{b}-\mathbf{g}$ Immunohistological analyses for collagen-I (Col-l; green; $\mathbf{b}$ and $\mathbf{e}$ ) and CD45 (red; $\mathbf{c}$ and $\mathbf{f}$ ) were performed with lung sections on day 28 after BLM treatment, with or without adoptive Treg transfer. The merged images (yellow; $\mathbf{d}$ and $\mathbf{g}$ ) represent co-staining for Col-I and CD45, indicating the presence of bone marrow-derived fibrocytes. Fibrocytes are indicated with arrows. The increased numbers of fibrocytes expressing Col-I and CD45 observed in BLM-treated mice were attenuated by adoptive Treg transfer. Nuclei were counterstained with 4,'6-diamidino-2-phenylindole. Original magnification, $\times 40$

was abolished by antibody-mediated Treg depletion. We further observed that BLM-induced lung fibrosis was attenuated by adoptive Treg transfer when they were transferred at the fibrotic stage, using our model. This effect was accompanied by Treg-mediated suppression of FGF9 and CCL2 production. Moreover, splenectomy performed simultaneously with BLM administration ameliorated fibrosis formation. These findings may provide evidence of an integral role for Tregs in the resolution of pulmonary fibrosis, which we believe to be a novel finding. These findings are expected to broaden our understanding of immunological mechanisms underlying the disease.

The role of inflammation along with the involvement of the immune response remains largely obscure in IPF pathogenesis. The implication of T cells in IPF development is controversial. Instead, evidence suggests that $\mathrm{T}$ lymphocytes may modulate inflammatory and healing responses in the lungs in a profibrotic or antifibrotic manner depending on their phenotype, and the balance between these functionally different $\mathrm{T}$ cell subsets may be a determining factor in the development of fibrosis
[10]. Immunosuppressive Tregs represent a novel $\mathrm{T}$ cell sub-population that is expected to act profibrotically [10]. Kotsianidis and colleagues, however, reported that in patients with IPF, Tregs were reduced compared with those of healthy volunteers and patients without IPF, and Treg activity was significantly impaired [9]. In support of these observations, Shimizu and colleagues showed that interstitial Foxp3-positive lymphocytes decreased in the lungs of patients with usual interstitial pneumonia [31]. Antithetically, Galati and colleagues found that Tregs were significantly increased in patients with IPF [11]. Thus, the roles that Tregs play in IPF development are still under debate.

These issues are similarly controversial in lung fibrosis animal models, and conflicting results have been found. In this study, Tregs adoptively transferred on day 14 post-BLM treatment significantly ameliorated BLMinduced murine pulmonary fibrosis; however, the role of Tregs on pulmonary fibrosis is still a matter of debate, as exemplified by a study in which Treg depletion attenuated the development of silica-induced lung fibrosis in 
a

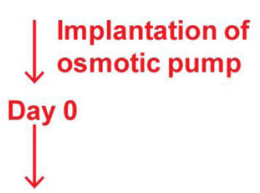

Bleomycin from day 0 to 6

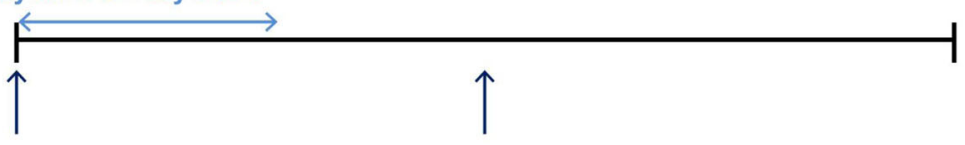

Splenectomy day 0

Splenectomy day 14

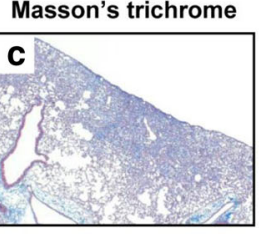

$\mathbf{f}$

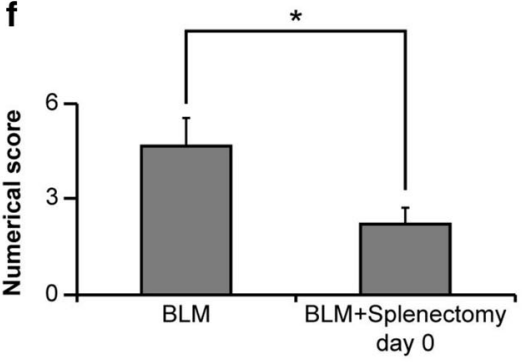

Fig. 8 Effect of splenectomies on bleomycin (BLM)-induced murine pulmonary fibrosis. Outline of experimental design used for splenectomies a. Osmotic pumps containing $200 \mu \mathrm{L}$ saline, with or without BLM were implanted subcutaneously through a small incision in the back according to the manufacturer's instructions. Then, spleen vessels were cauterized and the spleen was removed either on day 0 or 14 . On day 28 , mice were sacrificed and the right lungs were subjected to hematoxylin and eosin (HE) and Masson's trichrome staining. The extent of lung fibrosis was measured by quantitative histology, according to Ashcroft's method. Splenectomy on day 0 significantly ameliorated pulmonary fibrosis (b-f). Mice that underwent a splenectomy on day 14 were administered $60 \mathrm{mg} \mathrm{BLM} / \mathrm{kg}$ body weight to reduce the mortality caused by splenectomy on day $14 .{ }^{*} P<0.05 . \mathrm{n}=5$ mice/group. SPX; splenectomy

mice [32]. The discrete triggers involved in inducing lung fibrosis may partly explain these disparities. Consistent with our observations, Boveda-Ruiz and colleagues demonstrated that Treg depletion accelerated pulmonary fibrosis during the late stage of BLM-induced murine pulmonary fibrosis [12]. However, they also demonstrated that Treg depletion during the early stage in their model ameliorated pulmonary fibrosis, similar to results from Birjandi et al. where the adoptive transfer of Tregs aggravated BLM-induced lung fibrosis in mice when administered during early inflammatory phase [33]. In general, BLM administration induces acute panalveolitis during the first week, and the inflammatory response peaks on day 7 after beginning drug infusion [34, 35]. This early phase is followed by a late process characterized by enhanced myofibroblast proliferation and deposition of ECM proteins in the lungs. Hence, Boveda-Ruiz et al. [12] concluded that Tregs exert different roles in the early and late stages of pulmonary fibrosis. Taken together, these data suggest that the application of Tregs with animals in fibrotic stages is more likely to reflect clinical settings where therapy is initiated against established pulmonary fibrosis.
IL-10 has been shown to reduce many inflammatory reactions [36] and is thus recognized as an antiinflammatory cytokine possessing immunosuppressive properties. Arai et al. demonstrated that introduction of the IL-10 gene into mice inhibited BLM-induced lung injury in vivo [25], and a similar effect of IL-10 was confirmed by Nakagome et al. [26]. Conversely, IL-10 overexpression has been linked to the development of pulmonary fibrosis in vivo [37]. Thus, the exact contribution of IL-10 to the development of pulmonary fibrosis in vivo remains undetermined. With respect to IL-10 production in the lungs, the results of several in vivo studies have shown that IL-10 levels were unchanged or decreased by BLM administration [38, 39] while increased IL-10 protein concentrations were found in the plasma of treated animals [40]. We also observed a significant increase in plasma IL-10 levels in mice after a BLM challenge. Although we expected a further increase in IL-10 production by Treg transfer, plasma IL-10 levels were not changed, as compared with those in a salinetreated group. These data imply that increased IL-10 levels in mice receiving BLM may serve as a protective mechanism that may be overcome by a severe injury that 
ultimately results in fibrosis. To further explore the potential of IL-10 in the current model, we adoptively transferred Tregs from IL-10 knock-out mice. The results suggested that IL-10 from Tregs might have an impact on the resolution of BLM-induced pulmonary fibrosis, which supports the data from previous studies [25, 26]. Taken together, IL-10 could be considered to work not only as an anti-inflammatory but also as an anti-fibrotic mediator.

In this study, we removed spleens at different stages in a BLM-induced murine pulmonary fibrosis model. Most Foxp $3^{+}$natural Treg cells are produced by the thymus as an antigen-primed and functionally mature $\mathrm{T}$ cell subpopulation specialized for immune suppression [41]. Subsequently, they distribute to the peripheral lymph nodes and spleen. Monocytes have been reported to be produced in the bone marrow from hematopoietic precursors at steady state; however, during inflammation, the spleen is also involved in the generation, depot, and deployment of these cells [42]. Although BLM administration can reduce the splenic lymphocyte pool size [30], it is not known whether the spleen is involved in Treg deployment in this model. However, our current observation demonstrated that spleen removal at an early stage of the current model changed the course of BLMinduced murine pulmonary fibrosis. Moreover, the results were similar in part to those reported by BovedaRuiz et al., where removal of Tregs during the inflammatory phase ameliorates fibrosis [12]. These findings raised the possibility that the spleen is a reservoir of Tregs and contributes to disease progression.

This study has at least 3 principal limitations. First, although BLM-induced lung fibrosis is the best characterized and a widely used animal model for evaluating the therapeutic efficacy of experimental agents [34], it is impossible to completely recapitulate human IPF. However, experiments with BLM-induced pulmonary fibrosis in vivo have been utilized for the development of currently widely used anti-fibrotic agents, including pirfenidone [43] and nintedanib [44]. Hence, investigating the therapeutic efficacy in vivo with BLM-induced pulmonary fibrosis model appears to be an appropriate surrogate strategy for developing novel therapeutics. Second, the discrepant observations reported as the results of Treg administration may be attributed to different routes of BLM administration. Because various means of BLM challenge are available (including the intratracheal, intravenous, and intraperitoneal routes, as well as an osmotic pump as employed in this study), it is likely that differences in protocols used to induce lung fibrosis by BLM could explain the discrepant observations among the studies. Lastly, we could not clarify the detailed mechanisms by which Tregs resolve fibrosis in the current study. The role of Tregs was originally considered to suppress immune responses, although we could not directly demonstrate this point in the current model. However, recent reports suggest that Tregs have roles in tissue repair through the production of growth factors including keratinocyte growth factor (KGF) or amphiregulin [45], which have the potential to restore alveolar epithelial cell damage [46]. Therefore, studies to elucidate the tissue repair mechanisms promoted by Tregs should be considered using the current fibrosis model. However, such studies should be performed carefully because a recent report demonstrated that KGF treatment in patients with acute respiratory distress syndrome caused rather harmful effects [47].

\section{Conclusions}

In conclusion, Tregs significantly resolved BLM-induced murine pulmonary fibrosis when adoptively transferred in the fibrotic phase of the current model, which implicates the anti-fibrotic properties of Tregs in the chronic stage of the disease. Although the current study involved a single injection of Tregs during the course of the disease, repeated administration or ex vivo expansion of these cells is warranted to investigate the development of cell-based therapy for IPF.

\begin{abstract}
Abbreviations
BLM: Bleomycin; BSA: Bovine serum albumin; CCL2: Chemokine (CC motif) ligand-2; DAPI: 4',6-diamidino-2-phenylindole; ECM: Extracellular matrix; ELISA: Enzyme-linked immunosorbent assay; FGF: Fibroblast growth factor; HE: Hematoxylin and eosin; IL: Interleukin; IPF: Idiopathic pulmonary fibrosis; KGF: Keratinocyte growth factor; mAb: Monoclonal antibody; PBS: Phosphatebuffered saline; Tregs: Regulatory T cells
\end{abstract}

\section{Funding}

This work was supported by a Grant-in-Aid for Scientific Research from the Ministry of Education, Culture, Sports, Science and Technology of Japan (KKa). The study sponsor had no role in the study design; in the collection, analysis, and interpretation of data; in the writing of the report; or in the decision to submit the report for publication.

\section{Availability of data and materials}

All data generated or analyzed during this study are included in this published article.

\section{Authors' contributions}

$\mathrm{KKa}, \mathrm{AA}, \mathrm{KM}, \mathrm{JU}, \mathrm{MI}$, and $\mathrm{AM}$ participated in the study design, data analysis, and data interpretation; performed the statistical analysis; drafted the manuscript; revised the manuscript critically for important intellectual content; and (in the case of KKa) acquired funding. NN, SI, HH, TK, NK, KA, TY, KF, YS, SA, and KKu revised the manuscript critically for important intellectual content. AG participated in the study design and revised the manuscript critically for important intellectual content. All authors read and approved of the final manuscript.

\section{Ethics approval}

The experimental protocols were approved by the animal care and use committee of Nippon Medical School (Tokyo, Japan).

\section{Competing interests}

Azuma A. and Gemma A. acquired personal fees from Nippon Kayaku Co., Tokyo, Japan.

\section{Publisher's Note}

Springer Nature remains neutral with regard to jurisdictional claims in published maps and institutional affiliations. 


\section{Received: 4 October 2017 Accepted: 18 April 2018} Published online: 24 April 2018

\section{References}

1. Raghu G, Collard HR, Egan JJ, Martinez FJ, Behr J, Brown KK, et al. An official ATS/ERS/JRS/ALAT statement: idiopathic pulmonary fibrosis: evidence-based guidelines for diagnosis and management. Am J Respir Crit Care Med. 2011;183:788-824.

2. Ley B, Collard HR, King TE Jr. Clinical course and prediction of survival in idiopathic pulmonary fibrosis. Am J Respir Crit Care Med. 2011;183:431-40.

3. Tabuena RP, Nagai S, Tsutsumi T, Handa T, Minoru T, Mikuniya T, et al. Cell profiles of bronchoalveolar lavage fluid as prognosticators of idiopathic pulmonary fibrosis/usual interstitial pneumonia among Japanese patients. Respiration. 2005;72:490-8.

4. Wilson MS, Wynn TA. Pulmonary fibrosis: pathogenesis, etiology and regulation. Mucosal Immunol. 2009;2:103-21.

5. Homer RJ, Elias JA, Lee CG, Herzog E. Modern concepts on the role of inflammation in pulmonary fibrosis. Arch Pathol Lab Med. 2011;135:780-8.

6. Kolahian S, Fernandez IE, Eickelberg O, Hartl D. Immune mechanisms in pulmonary fibrosis. Am J Respir Cell Mol Biol. 2016;55:309-22.

7. Papiris SA, Kollintza A, Kitsanta P, Kapotsis G, Karatza M, Milic-Emili J, et al. Relationship of BAL and lung tissue CD4+ and CD8+ T lymphocytes, and their ratio in idiopathic pulmonary fibrosis. Chest. 2005;128:2971-7.

8. Parra ER, Kairalla RA, Ribeiro de Carvalho CR, Eher E, Capelozzi VL. Inflammatory cell phenotyping of the pulmonary interstitium in idiopathic interstitial pneumonia. Respiration. 2007;74:159-69.

9. Kotsianidis I, Nakou E, Bouchliou I, Tzouvelekis A, Spanoudakis E, Steiropoulos $\mathrm{P}$, et al. Global impairment of $\mathrm{CD}^{+} \mathrm{CD}^{2} 5^{+} \mathrm{FOXP3}^{+}$regulatory $\mathrm{T}$ cells in idiopathic pulmonary fibrosis. Am J Respir Crit Care Med. 2009;179:1121-30.

10. Luzina IG, Todd NW, lacono AT, Atamas SP. Roles of T lymphocytes in pulmonary fibrosis. J Leukoc Biol. 2008;83:237-44.

11. Galati D, De Martino M, Trotta A, Rea G, Bruzzese D, Cicchitto G, et al. Peripheral depletion of NK cells and imbalance of the Treg/Th17 axis in idiopathic pulmonary fibrosis patients. Cytokine. 2014;66:119-26.

12. Boveda-Ruiz D, D’Alessandro-Gabazza CN, Toda M, Takagi T, Naito M, Matsushima $Y$, et al. Differential role of regulatory $T$ cells in early and late stages of pulmonary fibrosis. Immunobiology. 2013;218:245-54.

13. Harrison JH Jr, Lazo JS. High dose continuous infusion of bleomycin in mice: a new model for drug-induced pulmonary fibrosis. J Pharmacol Exp Ther. 1987;243:1185-94.

14. Laxer U, Lossos IS, Gillis S, Or R, Christensen TG, Goldstein RH, et al. The effect of enoxaparin on bleomycin-induced lung injury in mice. Exp Lung Res. 1999:25:531-41.

15. Ashcroft T, Simpson JM, Timbrell V. Simple method of estimating severity of pulmonary fibrosis on a numerical scale. J Clin Pathol. 1988;41:467-70.

16. D'Alessio FR, Tsushima K, Aggarwal NR, West EE, Willett MH, Britos MF, et al. $\mathrm{CD}^{+}{ }^{+} \mathrm{CD} 25^{+} \mathrm{Foxp}^{+}$Tregs resolve experimental lung injury in mice and are present in humans with acute lung injury. J Clin Invest. 2009;119:2898-913.

17. Woessner JF Jr. The determination of hydroxyproline in tissue and protein samples of this amino acid. Arch Biochem Biophys. 1961;93:440-7.

18. Aono $Y$, Nishioka $Y$, Inayama $M$, Ugai M, Kishi J, Uehara $H$, et al. Imatinib as a novel antifibrotic agent in bleomycin-induced pulmonary fibrosis in mice. Am J Respir Crit Care Med. 2005;171:1279-85.

19. Yaekashiwa M, Nakayama S, Ohnuma K, Sakai T, Abe T, Satoh K, et al. Simultaneous or delayed administration of hepatocyte growth factor equally represses the fibrotic changes in murine lung injury induced by bleomycin. A morphologic study. Am J Respir Crit Care Med. 1997;156:1937-44.

20. Novak ML, Koh TJ. Macrophage phenotypes during tissue repair. J Leukoc Biol. 2013;93:875-81.

21. Zhao YL, Tian PX, Han F, Zheng J, Xia XX, Xue WJ, et al. Comparison of the characteristics of macrophages derived from murine spleen, peritonea cavity, and bone marrow. J Zhejiang Univ Sci B. 2017;18:1055-63.

22. Coffey E, Newman DR, Sannes PL. Expression of fibroblast growth factor 9 in normal human lung and idiopathic pulmonary fibrosis. J Histochem Cytochem. 2013;61:671-9.

23. Peng $X$, Moore MW, Peng $\mathrm{H}$, Sun $\mathrm{H}$, Gan $\mathrm{Y}$, Homer R, et al. CD4 ${ }^{+} \mathrm{CD} 25^{+} \mathrm{FoxP} 3^{+}$ regulatory Tregs inhibit fibrocyte recruitment and fibrosis via suppression of FGF-9 production in the TGF-beta1 exposed murine lung. Front Pharmacol. 2014;5:80

24. Pandiyan $\mathrm{P}$, Zhu J. Origin and functions of pro-inflammatory cytokine producing Foxp3 $3^{+}$regulatory T cells. Cytokine. 2015;76:13-24.
25. Arai T, Abe K, Matsuoka H, Yoshida M, Mori M, Goya S, et al. Introduction of the interleukin-10 gene into mice inhibited bleomycin-induced lung injury in vivo. Am J Physiol Lung Cell Mol Physiol. 2000;278:L914-22.

26. Nakagome K, Dohi M, Okunishi K, Tanaka R, Miyazaki J, Yamamoto K. In vivo IL-10 gene delivery attenuates bleomycin induced pulmonary fibrosis by inhibiting the production and activation of TGF-beta in the lung. Thorax. 2006:61:886-94

27. Ebihara $Y$, Masuya M, Larue AC, Fleming PA, Visconti RP, Minamiguchi $H$, et al. Hematopoietic origins of fibroblasts: II. In vitro studies of fibroblasts, CFU-F, and fibrocytes. Exp Hematol. 2006;34:219-29.

28. Abe R, Donnelly SC, Peng T, Bucala R, Metz CN. Peripheral blood fibroblasts: differentiation pathway and migration to wound sites. J Immunol. 2001;166: 7556-62.

29. Chesney J, Metz C, Stavitsky AB, Bacher M, Bucala R. Regulated production of type I collagen and inflammatory cytokines by peripheral blood fibrocytes. J Immunol. 1998;160:419-25.

30. Zhu J, Kaplan AM, Goud SN. Immunologic alterations in bleomycin-treated mice: role of pulmonary fibrosis in the modulation of immune responses. Am J Respir Crit Care Med. 1996:153:1924-30.

31. Shimizu Y, Dobashi K, Endou K, Ono A, Yanagitani N, Utsugi M, et al. Decreased interstitial FOXP3 ${ }^{+}$lymphocytes in usual interstitial pneumonia with discrepancy of CXCL12/CXCR4 axis. Int J Immunopathol Pharmacol. 2010;23:449-61.

32. Liu F, Liu J, Weng D, Chen Y, Song L, He Q, et al. CD4+CD25+Foxp3+ regulatory $T$ cells depletion may attenuate the development of silicainduced lung fibrosis in mice. PLoS One. 2010;5:e15404.

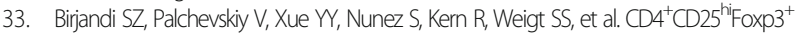
cells exacerbate bleomycin-induced pulmonary fibrosis. Am J Pathol. 2016;186:2008-20.

34. Moore BB, Hogaboam CM. Murine models of pulmonary fibrosis. Am J Physiol Lung Cell Mol Physiol. 2008;294:L152-60.

35. Yasui H, Gabazza EC, Tamaki S, Kobayashi T, Hataji O, Yuda H, et al. Intratracheal administration of activated protein $\mathrm{C}$ inhibits bleomycin-induced lung fibrosis in the mouse. Am J Respir Crit Care Med. 2001;163:1660-8.

36. Moore KW, Rousset F, Banchereau J. Evolving principles in immunopathology: interleukin 10 and its relationship to Epstein-Barr virus protein BCRF1. Springer Semin Immunopathol. 1991;13:157-66.

37. Sun L, Louie MC, Vannella KM, Wilke CA, LeVine AM, Moore BB, et al. New concepts of IL-10-induced lung fibrosis: fibrocyte recruitment and $M 2$ activation in a CCL2/CCR2 axis. Am J Physiol Lung Cell Mol Physiol. 2011;300:L341-53.

38. Garcia-Prieto E, Gonzalez-Lopez A, Cabrera S, Astudillo A, Gutierrez-Fernandez A, Fanjul-Fernandez $M$, et al. Resistance to bleomycin-induced lung fibrosis in MMP-8 deficient mice is mediated by interleukin-10. PLoS One. 2010;5:e13242.

39. Nakatani-Okuda A, Ueda H, Kashiwamura S, Sekiyama A, Kubota A, Fujita Y, et al. Protection against bleomycin-induced lung injury by IL-18 in mice. Am J Physiol Lung Cell Mol Physiol. 2005;289:L280-7.

40. Remund K, Rechsteiner T, Guo Z, Hofer M, Boehler A. Extracorporeal photopheresis in a rat model of pulmonary fibrosis. Exp Lung Res. 2009;35:359-70.

41. Ohkura N, Kitagawa Y, Sakaguchi S. Development and maintenance of regulatory T cells. Immunity. 2013;38:414-23.

42. Swirski FK, Nahrendorf M, Etzrodt M, Wildgruber M, Cortez-Retamozo V, Panizzi $P$, et al. Identification of splenic reservoir monocytes and their deployment to inflammatory sites. Science. 2009;325:612-6.

43. Oku H, Shimizu T, Kawabata T, Nagira M, Hikita I, Ueyama A, et al. Antifibrotic action of pirfenidone and prednisolone: different effects on pulmonary cytokines and growth factors in bleomycin-induced murine pulmonary fibrosis. Eur J Pharmacol. 2008;590:400-8.

44. Chaudhary NI, Roth GJ, Hilberg F, Muller-Quernheim J, Prasse A, Zissel G, et al. Inhibition of PDGF, VEGF and FGF signalling attenuates fibrosis. Eur Respir J. 2007;29:976-85

45. Arpaia N, Green JA, Moltedo B, Arvey A, Hemmers S, Yuan S, et al. A distinct function of regulatory T cells in tissue protection. Cell. 2015;162:1078-89.

46. Dial CF, Tune MK, Doerschuk CM, Mock JR. Foxp $3^{+}$regulatory T cell expression of keratinocyte growth factor enhances lung epithelial proliferation. Am J Respir Cell Mol Biol. 2017;57:162-73.

47. McAuley DF, Cross LM, Hamid U, Gardner E, Elborn JS, Cullen KM, et al. Keratinocyte growth factor for the treatment of the acute respiratory distress syndrome (KARE): a randomised, double-blind, placebo-controlled phase 2 trial. Lancet Respir Med. 2017:5:484-91. 